\title{
Prevalence of mental illness in a rehabilitation unit for older adults
}

\author{
D C Shah, M Evans, D King
}

\begin{abstract}
Summary
The prevalence of psychiatric disorders was studied in 78 elderly people in a rehabilitation unit for older adults. The patients were assessed using the Evans Liverpool depression rating scale, Hospital Anxiety and Depression scale and Mini-Mental State Examination. Twentyeight $(35.9 \%)$ patients were found to be depressed, 15 of these also had raised anxiety. Thirty-one $(41.0 \%)$ patients had significant cognitive impairment and 14 of these had associated depression. Only 33 $(42 \%)$ had no evidence of either cognitive impairment or mood disorder. On discharge, $20(25.6 \%)$ patients were on antidepressant treatment but only $50 \%$ of those had this diagnosis recorded on the discharge summary. Our results showed higher prevalence of depression in this situation compared with the reported prevalence of $20-30 \%$ in the acute hospital setting. We recommend that all patients undergoing rehabilitation should be routinely screened for depression as it is common and treatment will improve the overall outcome.
\end{abstract}

Keywords: depression; elderly; rehabilitation; psychiatric morbidity; screening

Depression is common in older adults, with a reported prevalence of $20-30 \%$ in the acute hospital setting, ${ }^{12}$ and it may present in various atypical forms. The types of presentation most often misdiagnosed are somatised depression, where the patient complains of physical rather than psychological symptoms of depression, and masked depression, where they may actively deny any mood problems, even to themselves. It is not known why depression may present with somatic symptoms..$^{3-6}$ The common complaints are tiredness, lethargy, and loss of appetite and poor concentration. Depression can present with anxiety with associated complaints of palpitations and breathlessness - in fact pure anxiety states without associated depression are rare in the elderly. Depression can reduce tolerance for an established physical problem, especially a painful one, leading to increased attendance at primary care and inability to cope with activities of daily living. Alternatively, the depression may lead to changes in behaviour which bring about physical problems, such as non-

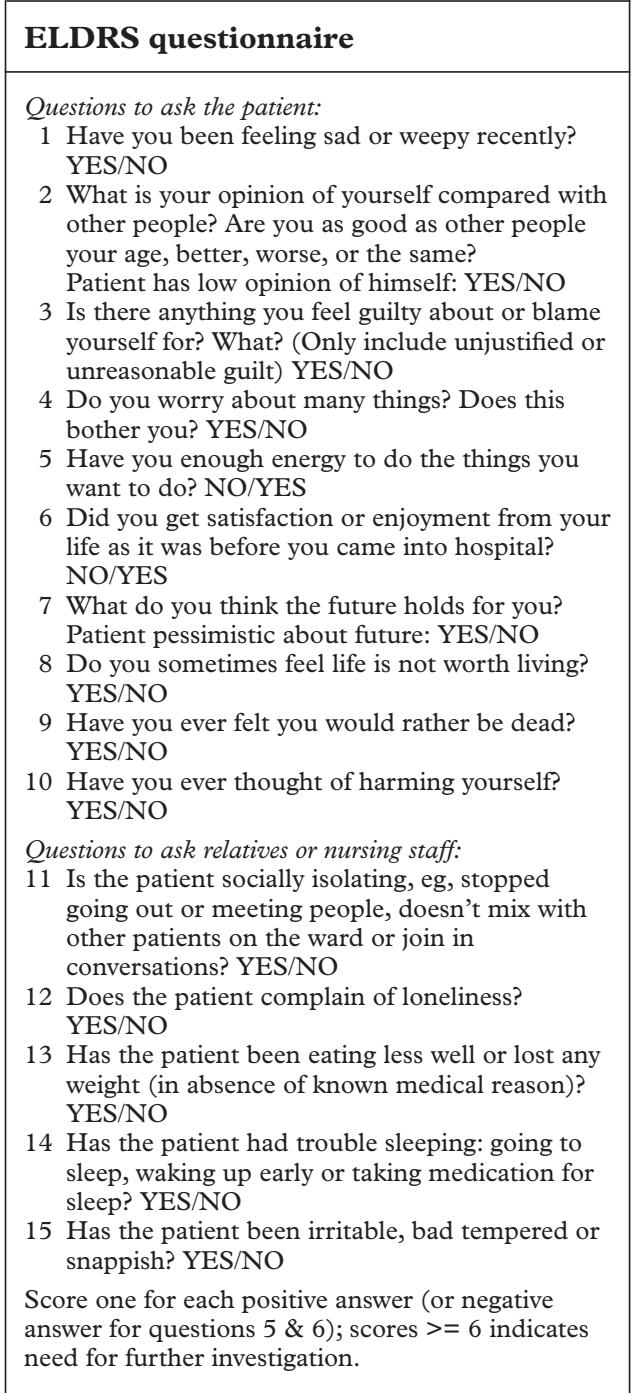

Box 1

compliance with medication, poor nutrition and reduced mobility. ${ }^{7}$

There are no diagnostic tests for depression. The ELDRS (Evans Liverpool depression rating scale, box 1) is specifically designed to screen for depression in physically ill elderly patients, including those with cognitive impairment, with a specificity of $95.5 \%$ and sensitivity of $87.5 \%^{8}$ against structured psychiatric examination. The observer-rated section of ELDRS allows corroborative information to be gathered, which is important when the patient 
Table 1 Psychiatric diagnoses $(n=78)$

\begin{tabular}{lcclll}
\hline & Depression & $\begin{array}{l}\text { Depression } \\
\text { and anxiety }\end{array}$ & Anxiety & $\begin{array}{l}\text { No mood } \\
\text { disorder }\end{array}$ & Total \\
\hline Cognitive impairment & 4 & 10 & 2 & 15 & 31 \\
No cognitive impairment & 9 & 5 & 0 & 33 & 47 \\
Total & 13 & 15 & 2 & 48 & 78 \\
\hline
\end{tabular}

\begin{tabular}{|l|}
\hline Symptoms of depression \\
\hline - a depressed mood, often worse in the morning \\
- lack of concentration \\
- pack of energy, tiredness and lethargy \\
- agitation, anxiety \\
- loss of interest (anhedonia) \\
- sleep disturbances \\
blame
\end{tabular}

Box 2

may be denying or somatising their psychological problems.

Depression and dementia are also frequently seen together. Depression can present with poor concentration and memory problems which, in a severe form, can be misdiagnosed as dementia. Correct diagnosis of this pseudodementia is important as it is reversible with correct treatment. ${ }^{9}$ Patients with a dementia may become depressed, particularly if they have insight into their condition. The mood problem will adversely affect the cognitive deficit; again this can be reversed with antidepressant treatment. Therefore, patients with a diagnosis of dementia should be carefully examined for evidence of depression.

In the Rehabilitation Unit for Older Adults, patients are admitted after stroke, hip replacement, other surgery, and with various major medical problems, eg, post-myocardial infarction, bronchopneumonia. The NIH Consensus statement ${ }^{10}$ on diagnosis and treatment of depression in later life states that it frequently occurs in patients with numerous social and physical problems which obscure the diagnosis and complicate the management. They advise vigorous treatment with a therapeutic dose of antidepressants for a sufficient length of time to maximize recovery and thus reduce morbidity.

\section{Materials and methods}

All patients admitted over a period of 3 months to the rehabilitation ward for older adults, were entered into the study $(n=92)$. The ELDRS questionnaire, ${ }^{8}$ Hospital Anxiety and Depression scale $(\mathrm{HAD})^{11}$ and Mini-Mental State Examinations (MMSE) ${ }^{12}$ were administered on or soon after admission by one observer (DS).

A diagnosis of depression was made if a patient scored six or more on ELDRS or more than 10 on HAD in the presence of clinical evidence of depression, ie, withdrawn and depressed mood, sleep disturbances, loss of appetite and other symptoms suggestive of depression (box 2). The diagnosis of depression was recorded in the case notes to inform the consultant for appropriate action. The patients' place of residence and mobility before admission and on discharge were also recorded. The case notes were audited on discharge to determine if the discharge letters detailed any significant mental illness and if any treatment had been commenced.

\section{Results}

Ninety-two patients were seen initially, 14 of whom were excluded from the analysis (three died, one exhibited severe communication difficulties and 10 could not complete the questionnaires). Of the remaining 78 patients, $45(58 \%)$ were given a psychiatric diagnosis (table 1).

Twenty-eight (36\%) patients were diagnosed as suffering from depression or depression with anxiety. Of these, 16 were already on antidepressants, as were eight further patients without mood disorder when seen. On discharge, 20 patients were on antidepressant treatment but only $50 \%$ had this diagnosis recorded on the discharge summary.

Fourteen patients screened positive for depression on the ELDRS and six on the HAD while eight patients showed evidence of depression on both ELDRS and HAD. ELDRS picked up a significantly higher proportion of depressed patients compared to HAD ( $p=0.05)$. Administration of both scales did not significantly improve the diagnosis of depression compare to ELDRS alone.

Mental state was also noted to affect outcome in terms of mobility and place of discharge, with a worse prognosis seen in those with dementia plus mood disorder (tables 2 and 3), although numbers are too small for further analysis by physical condition. Those without cognitive impairment were more likely to return to live at home, either alone or with their spouse, although this did not reach significance.

Table 2 Outcome by mobility

\begin{tabular}{|c|c|c|c|c|c|c|c|c|}
\hline & \multicolumn{4}{|l|}{ On admission } & \multicolumn{4}{|l|}{ On discharge } \\
\hline & Independent & Stick & $\begin{array}{l}\text { Zimmer } \\
\text { frame }\end{array}$ & $\begin{array}{l}\text { Not } \\
\text { mobile }\end{array}$ & Independent & Stick & $\begin{array}{l}\text { Zimmer } \\
\text { frame }\end{array}$ & $\begin{array}{l}\text { Not } \\
\text { mobile }\end{array}$ \\
\hline Dementia & 3 & 4 & 4 & 4 & 0 & 1 & 10 & 4 \\
\hline Dementia and mood disorder & 7 & 1 & 2 & 6 & 4 & 0 & 4 & 8 \\
\hline Mood disorder & 4 & 5 & 3 & 2 & 3 & 2 & 7 & 2 \\
\hline Well & 4 & 4 & 15 & 10 & 10 & 7 & 15 & 1 \\
\hline Total & 18 & 14 & 24 & 22 & 17 & 10 & 36 & 15 \\
\hline
\end{tabular}


Table 3 Outcome by place of discharge

\begin{tabular}{|c|c|c|c|c|c|c|c|c|}
\hline & \multicolumn{4}{|c|}{ On admission } & \multicolumn{4}{|c|}{ On discharge } \\
\hline & Alone & $\begin{array}{l}\text { With } \\
\text { spouse }\end{array}$ & $R H$ & $\mathrm{NH}$ & Alone & $\begin{array}{l}\text { With } \\
\text { spouse }\end{array}$ & $R H$ & $\mathrm{NH}$ \\
\hline Dementia & 6 & 8 & 1 & 0 & 2 & 5 & 2 & 6 \\
\hline Dementia and mood disorder & 8 & 6 & 2 & 0 & 1 & 3 & 2 & 10 \\
\hline Mood disorder & 10 & 3 & 1 & 0 & 7 & 2 & 2 & 3 \\
\hline Well & 22 & 11 & 0 & 0 & 14 & 8 & 7 & 4 \\
\hline Total & 46 & 28 & 4 & 0 & 24 & 18 & 13 & 23 \\
\hline
\end{tabular}

$\mathrm{RH}=$ residential home $\mathrm{NH}=$ nursing home

\section{Discussion}

The problem of differentiating between 'appropriate' distress, dysphoria, and depression in the elderly physically ill is well recognised. ${ }^{13}$ Somatic symptoms of depression such as loss of appetite, poor sleep, reduced energy and poor concentration can all be caused by physical illness. The symptoms may be attributed to a physical problem and depression missed, alternatively depression may be diagnosed erroneously. Although every effort should be made to minimise risk of either error, if doubt remains a trial of treatment with one of the safer antidepressants, such as the selective serotonin reuptake inhibitors (SSRIs), will elucidate the correct diagnosis and not delay correct treatment of the depressed patient. It must be remembered that antidepressant effect may take up to 8 weeks to occur in this age group. ${ }^{14}$

The elderly respond well to the SSRIs. ${ }^{15} 16$ These drugs are effective, well tolerated and comparatively safe, particularly in the elderly who are frequently on multiple medications. It should, however, be kept in mind that the elderly are more prone to side-effects. ${ }^{17}$

The results from this study show the worst outcome in terms of entry into residential or nursing care in those patients with dementia and depression. Successful treatment of depression has been shown to improve outcome and reduce length of stay, ${ }^{18}$ and may have been a factor in the results in the depressed group being similar to those in the psychologically well group.

When treating depression, supportive listening and discussion of the patient's worries is essential and should not be forgotten. In some cases antidepressants are not necessary, eg, depression caused by loneliness may be alleviated by attendance at a day centre or provision of regular home helps. ${ }^{19}$

Although the HAD diagnosed pure anxiety in two patients, it is likely that this was also a symptom of depression, which frequently presents as anxiety and/or irritability in the elderly: some studies find anxiety a more common complaint than sadness. ${ }^{20}$ Anhedonia (lack of pleasure or enjoyment in life) should be enquired for as well as depressed mood.

1 Hammond MF, Evans ME, Lye M. Depression in a medical ward. Int $\mathcal{F}$ Geriatr Psychiatry 1993;8:957-9.

2 Fenton FR, Cole MG, Engelsman N, Mansouri I. Depression in older medical inpatients. Int Clin Psychopharmacol 1993;8:333-6.

\section{Recommendations}

- patients admitted to rehabilitation units should be screened for depression

- educate doctors and nursing staff to suspect and enquire for depressive symptoms

- treatment of depression should be as intensive as treatment of the physical problems

\section{Learning points}

patients with dementia often have concomitant depression.

- elderly patients may present with physical symptoms rather than psychological problems

- depression is commonly associated with physical illnesses

- treating depression improves the outcome of rehabilitation

Box 4

Screening tests such as ELDRS carry no risk to the patient whereas non-diagnosis and therefore no treatment of depression causes increased morbidity and mortality. ${ }^{21-23}$ Screening must go hand-in-hand with education of both health service professionals and the general public about the potential for successful treatment of depression (box 3).

\section{Conclusion}

Rehabilitation is a process in which the medical, social and psychological needs of the patient are met to enable them to reach their maximum potential. This study shows the high prevalence of psychiatric morbidity on rehabilitation wards and emphasises the effect of screening tests in diagnosing depression - a treatable condition with high morbidity and mortality if untreated.

Depression is common among older adults. With the demographic shift towards an ageing population it will further increase what will be a high demand for health and social care. The early detection and treatment of depression can be improved by education of general medical and nursing staff, aided by routine administration of depression screening scales.

The prevalence of cognitive impairment increases with age and is often the deciding factor leading to admission to residential care. Concomitant depression can worsen the cognitive impairment and reduce skills in the activities of daily living. Minimising the problems by adequate treatment of depression may delay entry to care.

3 Evans ME. Depression in elderly physically ill inpatients: a 12 months prospective study. Int $\mathcal{f}$ Geriatr Psychiatry 1993; 8:587-92.

4 Stem RA, Bachman DL. Depressive symptoms following stroke. Am f Psychiatry 1991;148:351-6. 
5 Finch EJ, Ramsay R, Katona CL. Depression and physical illness in the elderly. Clin Geriatr Med 1992;8:275-87.

6 Collins E, Katona C, Orrell M. Diagnosis and managemen of depression in old age. Focus on Depression 1994;2:1-5.

7 Brodaty H. Think of depression - atypical presentations in the elderly. Aust Fam Physician 1993;22:195-203.

8 Evans ME. Development and validation of a brief screening scale for depression in the elderly physically ill. Int Clin Psychopharmacol 1993;8:329-31.

9 Kiloh LG. Pseudodementia. Acta Psychiat Scand 1961;37: 336-51.

10 Anonymous. Diagnosis and treatment of depression in late life: summary of the NIH consensus statement. Maryland Med F 1993;42:192-4

11 Zigmond AS, Snaith RP. The hospital anxiety and depression scale. Acta Psychiatr Scand 1983;67:361-70.

12 Folstein MF, Folstein SE, McHugh PR. "Mini Mental State". A practical method for grading the cognitive state of patients for the clinician. F Psychiatr Res 1975;12:189-98.

13 Silverstone PH. Measuring depression in the physically ill. Int f Meth Psychiatr Res 1991;1:3-12.

14 Georgotas A, McCue R. The additional benefit of extending an antidepressant trial past seven weeks in the depressed elderly. Int f Geriatr Psychiatry 1989;4:191-5.
15 Evans ME, Lye M. Depression in the physically ill, an open study of treatment with the 5-HT reuptake inhibitor fluoxstudy of treatment with the 5-HT reuptake
etine. F Clin Exp Gerontol 1992;14:297-307.

16 Donoghue J, Tylee A. The treatment of depression: prescribing patterns of antidepressants in primary care in the UK. Br f Psychiatry 1996;168:164-8.

17 Bazire S. Psychotropic Drug Directory: the professionals pocket handbook and aide-memoire. Wiltshire: Quay Books Division, Mark Allen Publishing Ltd, 1995; p 104.

18 Verbosky LA, Franco KN, Zrull JP. The relationship between depression and length of stay in the general hospibetween depression and length of stay in the

19 Wilson K. Rehabilitation of the elderly depressed. Adv Old Age Psychiatry 1992;4:5-7

20 Rohrbaugh RM, Siegel AP, Giller EL. Irritability as a symptom of depression in the elderly. F Am Geriatr Soc 1988;36: 736-8.

21 Robinson JR. The natural history of mental disorder in old age: a long term study. Br f Psychiatry 1989;154:783-9.

22 Baldwin RC, Jolley DJ. The prognosis of depression in old age. Br ₹ Psychiatry 1986;149:574-83.

23 Murphy E. The prognosis of depression in old age. Br f Psychiatry 1983;142:111-9.

\section{Medical Anniversary}

\section{Marcello Malpighi, 10 March 1628}

Marcello Malpighi (1628-1694) was born near Bologna, Italy, into a family of small landowners. He graduated in Bologna and became a successful lecturer there before moving to the chair of medicine in Pisa, thereafter to Sicily and a final return to Bologna. He made seminal observations on the structure and function of the kidney and upon the capillary circulation. In 1691, his friend Pope Innocent XII invited him to serve as his personal physician at the Quirinale Palace where he died. - DG fames 